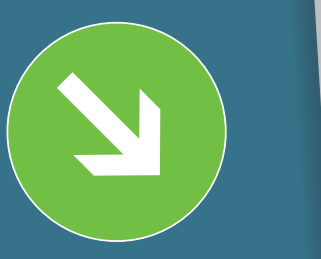

Ключевые слова: водосмешиваемые СОЖ, масляные СОЖ, мониторинг, концентрация, pH, биопоражение, электропроводность

\section{МОНИТОРИНГ И СЕРВИС СМАЗОЧНО-ОХЛАЖДАЮЩИХ ЖИДКОСТЕЙ}

\author{
Александр КЛЕПИКОВ, Татьяна КОШКИНА
}

После того как вы подобрали оптимальный продукт с учетом требований и условий технологического процесса, качества воды (в случае с водосмешиваемыми СОЖ), обрабатываемых сплавов и операций обработки, правильно приготовили эмульсию или раствор и заполнили подготовленную к замене систему подачи СОЖ (см. журнал «СТАНКОИНСТРУМЕНТ», 2019, № 3), начинается следующий, не менее важный этап обеспечения максимального срока службы жидкости с сохранением всех ее технологических и эксплуатационных характеристик.

В процессе резания металла участвуют четыре, влияющие на результат процесса и друг на друга, переменные: станок, инструмент, заготовка и смазочноохлаждающая жидкость. Предположим, что три первые переменныенадлежащим образом отслеживаются и корректируются для достижения максимальной производительности. Основываясь на опыте внедрения наших продуктов в технологическиепроцессы десятков предприятий, отметим, что важность поддержания четвертой переменной - предмета нашей беседы в оптимальном состоянии далеко не всегда осознается также остро, как в случае с остальными. В самых тяжелых случаях - к счастью, редких - в цехе никогда не

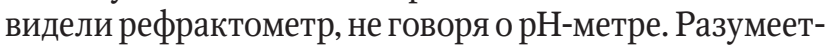
ся, при таком подходе предприятие не только не использует весь заложенный производителем потенциал самой жидкости, но и непрерывно борется за снижение количества брака и затрат на сервис станков, за повышение стойкости инструмента, а также с неприятными запахами, аллергическим дерматитом и прочими издержками неверного выбора продукта или несоблюдения элементарных правил его эксплуатации.
Итак, в этой статье мы обсудим мониторинг и сервис водосмешиваемых СОЖ в условиях предприятия. С мониторингом масляных СОЖ дела обстоят одновременно и проще, и сложнее. Мы затронем этот тип жидкостей в конце статьи.

Программа мониторинга и сервиса СОЖ начинает по-настоящему работать на заводе, только когда становится понятной важность жидкости для всего процесса. Убедиться в важности четвертой переменной можно, только когда программа работает. Похоже на замкнутый круг. Нам удалось его разорвать путем регулярного обучения сотрудников наших дистрибьюторов в регионах, в результате которого, по мере накопления опыта, сотрудник становится практически автономной единицей, способной организовать как программу испытаний продукта в ограниченном периоде времени, так и регулярный мониторинг. Благодаря развитию наших партнеров, мы можем предлагать предприятиям такую опцию, как сервисный контракт. Другими словами, предприятия теперь могут сосредоточиться на других составляющих производительности и не беспокоиться о СОЖ.

Перейдем непосредственно к теме статьи. Мониторинг состояния водосмешиваемых СОЖ в условиях завода заключается в регулярном измерении/ оценке следующих параметров:

$\rightarrow$ концентрации, \% - ежедневно;

$\rightarrow$ уровня $\mathrm{pH}-1-2$ раза в неделю;

$\rightarrow$ общего количества бактерий - ежемесячно или при резком снижении $\mathrm{pH}$, появлении неприятного запаха;

$\rightarrow$ дрожжей и плесневых грибков - ежемесячно; 
$\rightarrow$ электропроводности - 1 раз в неделю;

$\rightarrow$ уровня СОЖ в баке - ежедневно;

$\rightarrow$ появления неприятного запаха - ежедневно;

$\rightarrow$ появления следов коррозии на оборудовании или изделиях - ежедневно.

Также мы рекомендуем регулярно измерять в работающей СОЖ содержание нитритов несмотря на то, что их количество в настоящее время не нормируется нашим законодательством. Рекомендации связаны с тем, что некоторые водосмешиваемые СОЖ содержат в составе вторичные амины, способные реагировать с нитритами с образованием канцерогенных нитрозаминов. Для измерения содержания нитритов существуют специальные тестполоски.

Согласно стандарту TRGS 611, принятому в европейских странах, не рекомендуется контакт с жидкостью, содержание нитритов в которой составляет более 50 ppm (промилле).

Отметим, что наши продукты не содержат ни нитритов, ни вторичных аминов.

\section{КОНЦЕНТРАЦИЯ}

Без преувеличения, концентрация - самый важный параметр контроля состояния водосмешиваемых СОЖ. Если мы говорим о функциональных характеристиках, то вода в составе рабочей жидкости только охлаждает. Безусловно, эффективный отвод тепла из зоны резания крайне важен и для инструмента, и для детали, однако упрощенно можно сказать, что все остальные функции выполняют компоненты концентрата. Концентрат смазывает, защищает от коррозии, поддерживает механическую стабильность эмульсии, защищает от биопоражения, снижает износ инструмента, обеспечивает требуемую чистоту поверхности, очищает рабочую зону и т. Д.

Минимальное значение концентрации обуславливается, в основном, требованиями конкретного технологического процесса (обрабатываемый сплав, операции обработки, режимы резания), способностью готового продукта обеспечить достаточную защиту от коррозии и достаточную биостабильность. Максимальное значение ограничивается чувствительностью оператора к компонентам продукта, вероятностью повышенного пенообразования, появления отложений в станке, замасливания шлифовального инструмента и, конечно, экономическими соображениями.

В условиях завода самым распространенным методом измерения концентрации является измерение портативным рефрактометром. Это оптический прибор - цифровой или аналоговый, измеряющий показатель преломления светового потока, проходящего через образец.

\section{1. ПРОЦЕСС ИЗМЕРЕНИЯ КОНЦЕНТРАЦИИ АНАЛОГОВЫМ РЕФРАКТОМЕТРОМ}

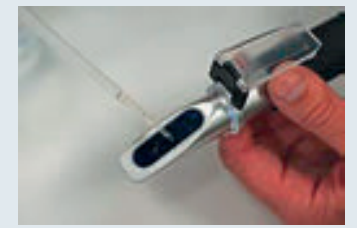

Нанесите на предметное стекло прибора несколько капель воды, которая используется для приготовления СОЖ.

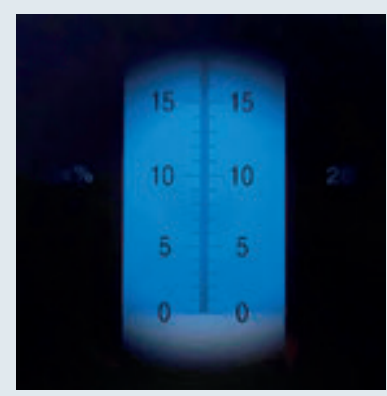

Посмотрите в объектив. Граница раздела областей разных цветов должна быть на отметке 0 .

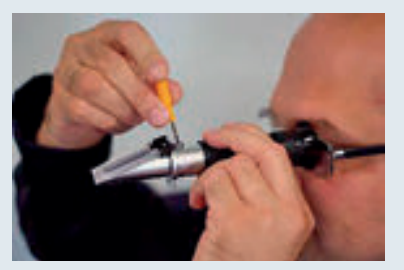

Если это не так, с помощью прилагаемой отвертки установите границу на ноль. После установки ноля протрите предметное стекло салфеткой и нанесите на него образец соЖ.

Процессы измерения для обоих типов приборов показаны ниже (см. врезы 1 и 2).

Вероятность роста концентрации в процессе работы СОЖ значительно выше, чем снижения, из-за интенсивного выпаривания воды. Для доведения концентрации до расчетных значений в этом случае в систему нельзя добавлять воду. Добавляется толь- 
ко слабоконцентрированная (1-2\%) эмульсия. Об этом говорят практически все производители жидкостей для металлообработки и совершенно обоснованно. Добавление воды может нарушить механическую стабильность рабочей жидкости, а также спровоцировать нарушение технологического процесса, если не успевшая полноценно войти в состав готового продукта вода попадет в зону резания.

Основной причиной заниженной концентрации является отсутствие ее периодического контроля.

Действия здесь обратные, то есть в систему добавляется высококонцентрированная эмульсия. Возможно добавление чистого концентрата, однако в этом случае приступать к работе на станке придется на 20-30 мин позже, предоставив возможность жидкости тщательно перемешаться в процессе циркуляции «вхолостую». В централизованные системы, не оснащенные перемешивающими устройствами, настоятельно рекомендуется добавлять только высококонцентрированную эмульсию.

Существуют и другие методы, основанные на измерении в образце количества определенных компонентов или групп компонентов, например титрование,

\section{2. ПРОЦЕСС ИЗМЕРЕНИЯ КОНЦЕНТРАЦИИ ЦИФРОВЫМ РЕФРАКТОМЕТРОМ}

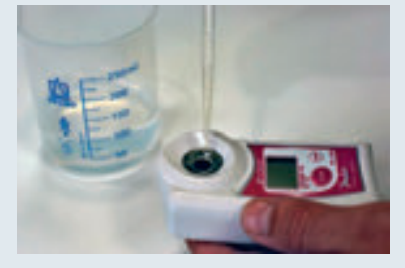

Заполните измерительное углубление прибора используемой на предприятии водой приблизительно на $70-80 \%$.

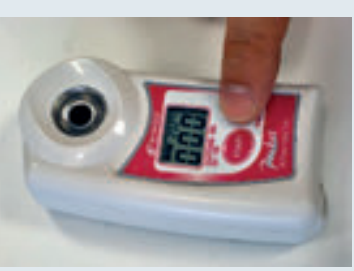

Нажмите кнопку Zero или Cal на приборе. Прибор автоматически установится на «ноль».

Удалите воду. Протрите углубление салфеткой. газовая хроматография, инфракрасная спектроскопия и т. д., однако такие тесты требуют лабораторных условий и наличия квалифицированного персонала.

При этом есть по меньшей мере одна веская причина потратить время и средства на анализ концентрации в лаборатории - значительное количество постороннего масла в СОЖ.

Постороннее масло может попасть в рабочую жидкость с направляющих скольжения, из гидравлической системы или из системы привода в случае утечек вследствие неисправности.

В такой ситуации граница раздела на аналоговом приборе размывается (рис. 1), а цифровой прибор показывает некорректные цифры. Если вы видите размытую границу в объективе аналогового прибора и визуально наблюдаете постороннее масло на поверхности рабочей жидкости, то образец необходимо направить в лабораторию.

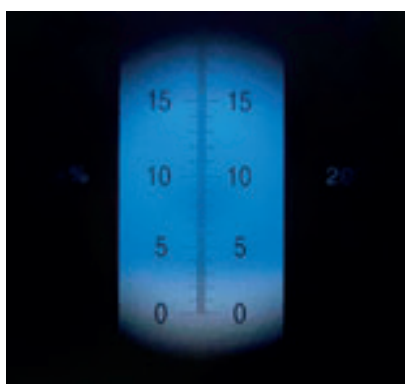

Puc. 1.

Размытые границы между областями разных цветов

Важно отметить, что искажение показаний рефрактометра - это наименьший вред от постороннего масла в СОЖ. Масло, попавшее в рабочую жидкость, может либо эмульгироваться, либо оставаться в свободном виде на поверхности жидкости. Свободное масло образует пленку, препятствующую доступу кислорода в жидкость, создавая благоприятные условия для роста анаэробных бактерий. Представители именно этого вида бактерий чаще всего провоцируют появление неприятных запахов. Кроме того, попадание свободного масла в зону резания может привести к нарушению технологии обработки, поскольку в процессе начинает участвовать не подобранная под него жидкость, а предназначенное для других целей масло. Эмульгированное масло «отвлекает на себя» эмульгаторы, при этом не несет в себе всего заложенного в концентрат СОЖ функционала. Конечным результатом этого процесса может быть образование сгустков и расслоение эмульсии.

Здесь становится очевидной необходимость дооснащения станков устройствами для удаления масла с поверхности, пока оно находится в свободном виде скиммерами. Тип, производительность и размер этих устройств необходимо подбирать индивидуально, и мы готовы помочь в этом нашим партнерам.

В заключение раздела отметим, что цифровые приборы обеспечивают более точные результаты 
в более широком диапазоне концентраций, и вложения в такой прибор окупаются в течение одного цикла работы СОЖ.

Также добавим, что для некоторых водосмешиваемых жидкостей для металлообработки, например промышленных очистителей и некоторых закалочных жидкостей, метод измерения рефрактометром не подходит, однако если мы говорим о контроле СОЖ для обработки металлов резанием в условиях завода, этот метод безальтернативный.

\section{$\mathrm{pH}$}

Водородный показатель мы затронули в общих чертах в предыдущей статье, когда говорили о воде. По информативности в рамках мониторинга состояния СОЖ этот параметр можно сравнить с температурой тела человека. Еще одну параллель к этому сравнению может добавить простота и оперативность измерения обоих индикаторов здоровья «пациентов». Процесс измерения $\mathrm{pH}$ и калибровки прибора в условиях предприятия показаны на врезе 3.

Некоторые цифровые портативные приборы требуют калибровки перед каждым измерением, некоторые - с определенной периодичностью во времени. Мы рекомендуем проводить эту процедуру перед каждым измерением или серией измерений в нескольких станках, благо, калибровочные растворы стоят недорого, а сама процедура проста и сходна для всех подобных приборов.

Компоненты водосмешиваемых СОЖ с содержанием минерального масла оптимально работают в слабощелочной среде, в диапазоне $\mathrm{pH}$ в среднем от 8,5 до 10. Композиции синтетических СОЖ могут быть рассчитаны на почти нейтральную среду с $\mathrm{pH}$ порядка 7,5 единиц. Это должно быть обусловлено применением, в частности - обрабатываемыми сплавами. Например, СОЖ Castrol Syntilo 9913, предназначенная для обработки авиационных сплавов алюминия и титана, имеет начальный $\mathrm{pH} 3 \%$-ного раствора порядка 7,4 с целью исключить окрашивание деталей.

Рост рН в работающей СОЖ может быть вызван двумя причинами: увеличением концентрации, часто в результате ошибки при пополнении системы; попаданием в систему жидкости с высокой щелочностью, например промышленного очистителя от промежуточной промывки детали или дополнительной присадки в ошибочно высокой концентрации (корректор рН, биоцид, ингибитор коррозии). О негативных последствиях контакта операторов с жидкостью высокой щелочности мы писали в предыдущей статье.

Снижение уровня $\mathrm{pH}$ работающей СОЖ - это нормальный процесс. Вопрос в том, насколько быстро падает значение и до какого уровня. Резкое снижение

\section{3. КАЛИБРОВКА рН-МЕТРА}

Налейте калибровочный раствор в подходящую емкость, опустите в нее электрод прибора и включите его.

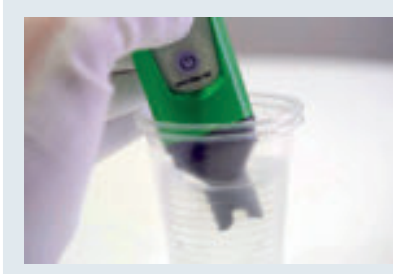

Если показания отличаются от заданного в растворе значения, нажмите кнопку Cal на приборе.

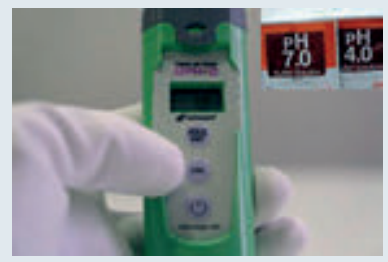

На экране появится надпись Cal.

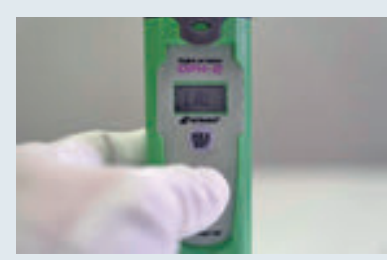

Далее процесс происходит автоматически, остается только дождаться появления корректного значения на экране и окончания калибровки, о котором известит надпись «End». До появления этой надписи процесс прерывать не рекомендуется. Калибровку необходимо делать как минимум по «двум точкам», то есть использовать два калибровочных раствора с разными значениями $\mathrm{pH}$.

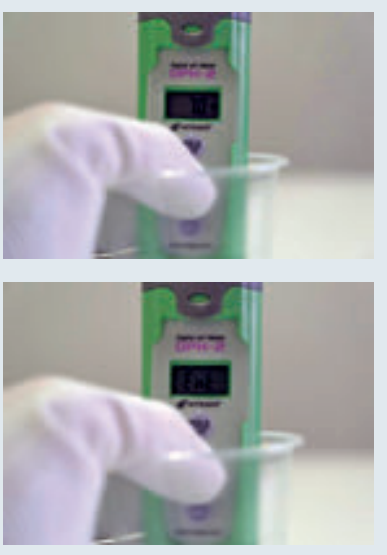

\section{Измерение $\mathrm{pH}$}

После калибровки электрод прибора необходимо промыть водой. Разный материал электродов диктует разные требования к качеству воды для промывки, поэтому инструкцию всетаки необходимо предварительно прочитать. После промывки прибор готов к работе. Опустите электрод в образец жидкости и включите его.

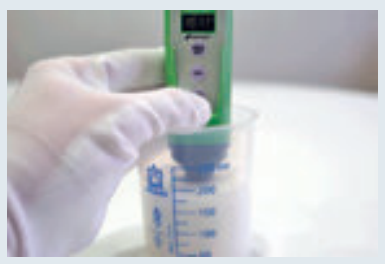

Подождите несколько секунд, пока показания не станут более или менее стабильными. Запишите показания прибора в лист контроля, который удобно расположить прямо на корпусе станка при помощи магнита. Сотрудники наших дистрибьюторов предоставляют заводам шаблоны этих документов еще на этапе испытаний. 


\section{4. ИЗМЕРЕНИЕ/ ПОДСЧЕТ ОБЩЕГО ЧИСЛА БАКТЕРИЙ И ГРИБКОВ}

Открутите крышку и извлеките слайд, не касаясь питательной среды.

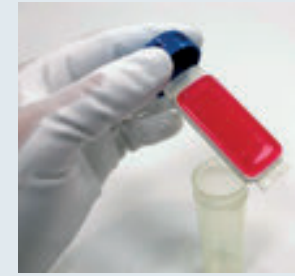

Погрузите слайд в емкость с предварительно отобранной пробой СОЖ, подождите несколько секунд.

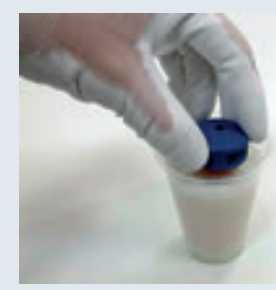

Дайте избыточной жидкости стечь со слайда.

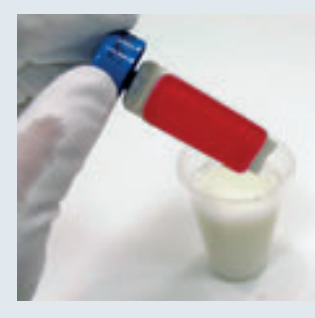

Промокните край слайда чистой салфеткой. Если этого не сделать, испарения жидкости затруднят считывание после инкубации.

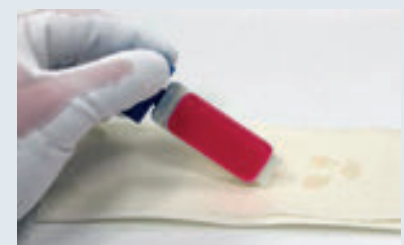

Поместите слайд в пробирку и плотно закрутите крышку.

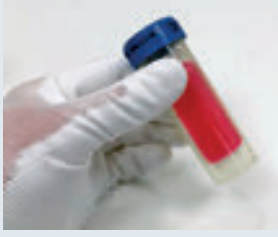

Нанесите данные о пробе прямо на пробирку или наклейку, если прилагается. Не забудьте указать дату начала инкубации.

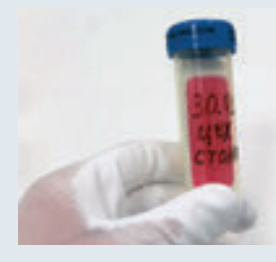

Поставьте пробирку в защищенном от солнечных лучей месте при комнатной температуре. Считывание показаний общего числа бактерий можно производить через 2-4 дня (см. инструкцию от каждого производителя). Для получения данных o грибках необходимо выдержать пробирку 4-7 дней в тех же условиях. ВАЖНО: не откручивайте крышку и не пытайтесь ощутить аромат продуктов метаболизма - это может нанести вред здоровью! После инкубации визуально сравните плотность выросших на питательной среде колоний с шаблонами в прилагаемой инструкции. ВАЖНО: после измерений дипслайды необходимо утилизировать в соответствии с инструкцией производителя!

\section{Примеры различных степеней биопора- жения}
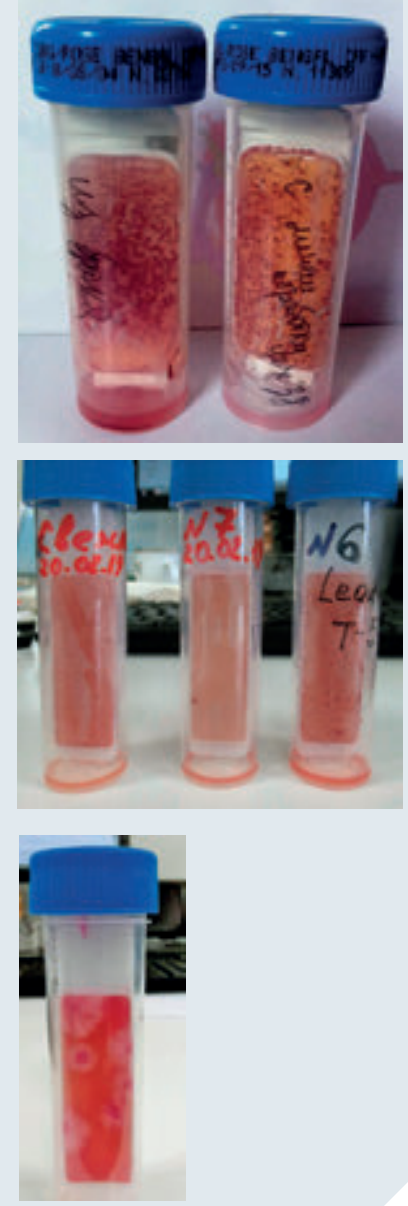

pH чаще всего указывает на бурный рост микроорганизмов, продукты метаболизма которых имеют кислую реакцию. Именно по падению $\mathrm{pH}$ проводится раннее диагностирование биопоражения, когда СОЖ еще можно «реанимировать» добавлением бактерицида. О биодеградации и биопоражении рабочей жидкости мы вкратце рассказали в предыдущей статье, поэтому здесь речь идет только о практических шагах. Итак, для $\mathrm{pH}$ нет установленного предельного значения, учитывается, прежде всего, динамика снижения этого параметра, и, если наблюдается резкое снижение в сравнении спредыдущими измерениями в том же промежутке времени, незамедлительно проводится измерение общего числа бактерий и грибков. В любом случае, при падении значения $\mathrm{pH}$ ниже 7 СОЖ подлежит замене из-за опасности возникновения коррозии. В нашей практике такие критические значения не встречались, однако других «опорных точек» в виде конкретных значений, к сожалению, нет.
Если при регулярном мониторинге вы обнаружили относительно резкое снижение значения $\mathrm{pH}$, необходимо уточнить его причину. Для измерения численности колониеобразующих единиц (КОЕ) бактерий и уровня поражения грибками существуют простые и относительно недорогие приспособления - так называемые дипслайды (dip - погружение, макание; slide - предметное стекло, пластина). Пластины дипслайдов покрыты питательной средой, на которой инкубируются микроорганизмы. Удобнее всего использовать двусторонние дипслайды, с питательными средами и для бактерий, и для грибков, нанесенными на разные стороны пластины. Процесс проведения измерений описан во врезе 4.

Существуют разные мнения о критическом значении общего количества бактерий. Это вполне обосновано, учитывая ограничения метода измерений и разную стойкость продуктов к биопоражению. Метод инкубирования на дипслайдах отличает- 
ся простотой, мобильностью и доступностью в отношении затрат. С другой стороны, с помощью этого метода мы получаем лишь порядок цифр численности бактерий, то есть $100 \mathrm{KOE} / \mathrm{Mл} \mathrm{(КОЕ/мл} \mathrm{-}$ колониеобразующих единиц на мл.), 1000 КОЕ/мл, 10000 КОЕ/мл и т. д. Кроме того, какая-то одна питательная среда просто не может обеспечить рост всех существующих штаммов микроорганизмов. Слишком разнообразен мир микробов.

Что касается стойкости эмульсии или раствора к биопоражению, иначе говоря, биостабильности, то эта характеристика выражена по-разному у различных типов СОЖ и у разных производителей. Мы наблюдали полную работоспособность и стабильный pH наших продуктов при общем количестве бактерий порядка $10^{5}$ и даже $10^{6} \mathrm{KOE} / \mathrm{Mл.} \mathrm{Эти} \mathrm{значения}$ в большинстве источников признаются критическими. Такая численность «достигалась» по двум причинам: недопустимо низкая концентрация вследствие отсутствия контроля или из соображений сиюминутной экономии затрат; бактерии непрерывно поступали в систему вместе с водой при пополнении.

Что же касается грибков, то любое их количество в системе недопустимо. Даже если производитель дипслайдов обозначает эталонный результат инкубации грибков как «незначительное заражение», необходимо в кратчайшие сроки провести обработку жидкости фунгицидом. Подробнее о профилактике заражения грибками - в предыдущей статье.

Высокий уровень биостабильности СОЖ - это замечательно, но зачем же устраивать в цехе ферму по выращиванию микробов? Микроорганизмы в любом случае снижают срок службы даже самых стойких продуктов и, учитывая все потенциальные риски, значительно дешевле организовать на предприятии водоподготовку и мониторинг. Например, обработанная обратным осмосом вода не только избавлена от солей, но и от подавляющего большинства микроорганизмов. Важно отметить, что установка обратного осмоса сама может стать источником заражения, если ее не обслуживать с установленной производителем периодичностью.

Далее, получив «сводку» об ориентировочной численности противника, можно приступать к наступлению. Подразумевая максимальную эффективность рабочей жидкости, мы рекомендуем начать это делать уже при $10^{5} \mathrm{KOE} / \mathrm{Mл.} \mathrm{При} \mathrm{этом}$ в распоряжении завода есть два вида «оружия»биоцид и вещества, непосредственно корректирующие рН в виде дополнительных присадок. Отметим, что продукты семейств Castrol Hysol, Alusol и Syntilo поддерживают настолько стабильный $\mathrm{pH}$ в процессе работы, что нам пока не приходилось использовать корректоры $\mathrm{pH}$ на российских предприятиях. Однако, если возникнет необходимость, в поставляемом ассортименте есть продукт $\mathrm{pH}$
Adjuster 401. Бактерициды (против бактерий) или фунгициды (против грибков) иногда приходится добавлять. Чаще всего такая потребность возникает в цехах, где не водится рефрактометр и рН-метр. Мы используем биоциды от компании THOR. У этой компании их насчитываются десятки, однако опытные специалисты-микробиологи высокой квалификации с радостью вам помогут с выбором.

Резюмируя, если вы обнаружили резкое снижение $\mathrm{pH}$ в совокупности с биопоражением, то весьма желательно одновременно использовать биоцид и корректор рН. Дальнейший мониторинг должен показать эффективность или тщетность принятых мер и предоставить информацию для дальнейших действий, вплоть до замены рабочей жидкости.

\section{ЭЛЕКТРОПРОВОДНОСТЬ}

В этом разделе, на наш взгляд, нелишне повторить информацию из предыдущей статьи.

Электропроводность показывает общее количество всех электролитов в жидкости, в том числе солей жесткости. Электролиты проводят электрический ток, поэтому следствием их высокого содержания в жидкости может стать электрохимическая коррозия. Кроме того, на эмульгаторы негативно влияют не только соли жесткости, но и другие соли, ионы которых могут реагировать с некоторыми типами эмульгаторов, «выключая» их из работы. В конечном итоге, это может привести к разделению эмульсии на водную и масляную фазы, а значит, к необходимости ее замены. Для целей мониторинга работающей СОЖ вполне подходят недорогие портативные приборы - кондуктометры. К сожалению, эти приборы, равно как и TDS-метры, неспособны отдельно определить количество солей жесткости, о которых мы писали в предыдущей статье о воде.

Количество солей жесткости можно точно определить только в специализированной лаборатории. Хорошая новость состоит в том, что в прошлом году совместно с крупнейшей независимой лабораторией в России мы наладили процесс анализа работающих СОЖ, который включает в себя определение количества солей кальция и магния. Лабораторный анализ водосмешиваемых СОЖ достоин стать темой следующей статьи.

\section{МОНИТОРИНГ МАСЛЯНЫХ СМАЗОЧНО- ОХЛАЖДАЮЩИХ ЖИДКОСТЕЙ}

Обслуживание систем, работающих с масляными смазочно-охлаждающими жидкостями, может показаться более простым по сравнению с таковым для систем, где работают водосмешиваемые СОЖ, и вызвано это ощущение отсутствием среды обитания микроорганизмов, а именно воды. Отсутствие воды избавляет от необходимости контроля концен- 
трации как таковой, еженедельного измерения уровня $\mathrm{pH}$ и ежемесячного измерения уровня биопоражения. Кроме того, срок службы масляных СОЖ может в несколько раз превышать срок службы водосмешиваемых, если в системе предусмотрена очистка от механических и жидкостных примесей.

Однако сложность в осуществлении мониторинга СОЖ этого типа заключается в том, что скольконибудь точно измерить контролируемые физикохимические характеристики возможно только в условиях лаборатории. Другими словами, сегодня не существует портативных «полевых» приборов для их измерения, которые не требуют специальных навыков и специального помещения. При этом даже при наличии на предприятии лаборатории со всем необходимым оборудованием ситуация осложняется отсутствием общепринятых критических значений этих параметров. В каждом случае эти значения определяются индивидуально, на основании таких косвенных показателей, как снижение стойкости инструмента, ухудшение чистоты обработки поверхности, размерной точности, а также появление следов коррозии на изделиях. Отклонение в одном или нескольких из них, при прочих равных, говорит о недопустимом ухудшении технологических характеристик (функциональных действий) СОЖ. При наличии результатов анализа регулярно отбиравшихся проб продукта необходимо зафиксировать цифры в протоколе ближайшего к моменту обнаружения отклонения анализа и сопоставить их с данными в протоколе предыдущего анализа. Ориентировочными значениями физикохимических характеристик для принятия решения о замене являются те, которые были получены при анализе предыдущей пробы. Периодичность отбора проб при таком подходе должна быть не реже одного раза в месяц. Далее выделим релевантные с точки зрения мониторинга работающей СОЖ контролируемые параметры и методы их измерения:

1. Кинематическая вязкость при $40^{\circ} \mathrm{C}$ (ASTM D445). Изменение кинематической вязкости происходит либо по причине попадания постороннего масла, либо в результате старения самой смазочно-охлаждающей жидкости.

2. Содержание воды по Карлу Фишеру (ASTM $\mathrm{D} 1744)$. Вода по сравнению с углеводородами не обладает смазывающей способностью. Кроме того, как мы упоминали выше, вода является средой обитания микроорганизмов.

3. Число омыления (DIN 51 559) характеризует содержание в продукте свободных жирных кислот и их эфиров. Отметим, что жирные кислоты и их эфиры как в составе растительных и животных жиров, так и синтезированные добавляются в СОЖ для улучшения смазывающей способности. Если быть более точными, эти вещества обеспечивают смазывание в граничном режиме, преобладающем в операциях обработки резанием. Снижение числа омыления указывает, прежде всего, на разбавление посторонним минеральным маслом и, соответственно, ухудшение смазывающей способности.

4. Общее кислотное число (ASTM D664) показывает количество кислотных компонентов в смазочно-охлаждающей жидкости. Необходимо учитывать, что анализ образца свежего продукта покажет определенное начальное значение этого параметра, влиять на которое в том числе будут свободные жирные кислоты. Повышение же этого значения от начального говорит об образовании продуктов окисления масла, которые, в свою очередь, могут стать причиной коррозии изделий и оборудования, образования отложений и снижения технологических характеристик СОЖ.

5. Тест на четырехшариковой машине трения. Нагрузка сваривания (ASTM D2596) дает нам информацию о количестве и состоянии противозадирных присадок. В процессе работы СОЖ эти присадки неизбежно расходуются, в результате чего значение нагрузки сваривания в этом тесте снижается.

6. Температура вспышки в открытом тигле (ASTM D92). Одним из результатов процессов окисления минеральных масел является разделение на легкие и тяжелые фракции, что влечет за собой снижение значения этого показателя. Кроме того, в СОЖ могут попасть жидкости, использовавшиеся на предыдущих этапах технологического процесса, например очистители или антикоррозионные составы на основе растворителей. Такие жидкости имеют значительно более низкую температуру вспышки, и разбавление ими, безусловно, повлияет на этот показатель. Температура вспышки СОЖ имеет непосредственное отношение к безопасности на производстве.

Резюмируя сказанное выше, мониторинг масляных смазочно-охлаждающих жидкостей на практике оказывается более сложным, требующим специального оборудования, навыков и наработки значительного массива эксплуатационных данных процессом.

В завершение хотелось бы сказать, что фундаментом мониторинга является регулярность. Казалось бы, очевидная мысль, однако, основываясь на опыте, думаю, что ее повторение не окажется лишним.

\section{КЛЕПИКОВ Александр - \\ технический консультант по маслам для промыш- ленных предприятий компании Castrol Россия}

\section{КОШКИНА Татьяна -}

кандидат биологических наук, технический специалист компании THOR GMBH 
